\title{
Cell subpopulations in failed human corneal grafts
}

\author{
Lucia Kuffová, Vladimír Holán̆, Lynne Lumsden, John V Forrester, Martin Filipec
}

Department of Ophthalmology, Charles University, Prague, Czech Republic

L Kuffová M Filipec

Institute of Molecular Genetics, Academy of Sciences, Prague,

Czech Republic

V Holán

Department of Ophthalmology, University of Aberdeen, Aberdeen, Scotland

L Kuffová

L Lumsden

J V Forrester

Correspondence to: $M$ Filipec, $\mathrm{MD}, \mathrm{PhD}$, Department of

Ophthalmology, Charles

University, U nemocnice 2 ,

12800 Prague, Czech

Republic

Accepted for publication 2 July 1999

\begin{abstract}
Backgroundlaims-Inflammatory cells and antigen presenting cells (APC) are not present under normal circumstances in the centre of the healthy cornea. The purpose of this study was to investigate and phenotype the inflammatory cell populations, particularly with reference to $T$ cell subpopulations and macrophages, and to localise dendritic cells (DC) and other MHC class II positive cells in three groups of grafted corneas: rejected noninflamed, rejected inflamed grafts, and control dystrophic explants.
\end{abstract}

Methods-15 corneal buttons removed during keratoplasty from non-inflamed "quiet" previously grafted corneas, five inflamed corneas requiring urgent regrafting for "graft melting" (in "high risk" corneas), and 10 control dystrophic opaque corneas explanted during their first graft procedure were examined. Cryosections of corneas were immunostained with a panel of monoclonal antibodies (mAb) against CD3, CD4, CD8, CD14, CD25, CD68, HLA-DP, and HLA-DR molecules using the StreptABC method. DC were detected by dual immunostaining as CD1a+ and MHC class II+ and CD19-. Cell densities in immunostained tissue sections were evaluated using a scale from 0 to +4 .

Results-Immunostaining in control dystrophic corneas was negative for all antibodies. A moderate to high density of CD8+, CD14+, and CD68+ cells was observed in the majority of rejected non-inflamed as well as in rejected inflamed corneal buttons. Strong positivity for HLA-DP and HLA-DR molecules in the epithelium, stroma, and endothelium was also demonstrated. Weak positivity for CD4 and CD25 was observed in six of 15 and 11 of 15 rejected corneas, respectively. The presence of dendritic cells in the basal layer of the epithelium and in the stroma was observed in $50 \%$ of the grafts.

Conclusions-A high frequency of macrophages, the presence of DC in the explants, and strong expression of HLA-DP and HLA-DR molecules on resident cells are characteristics of rejected corneal allografts, whether actively inflamed or not. The presence of DC in the stroma of the grafted cornea suggests that they may be mainly responsible for $T$ cell activation and graft rejection since $\mathrm{DC}$ are known to be a 100-fold more potent than macrophages as APC.

(Br f Ophthalmol 1999;83:1364-1369)
Keratoplasty represents the most common and successful transplantation of solid tissue in humans. For example, in the United States alone, more than 30000 corneas were grafted in 1985 and 43000 in $1993 .{ }^{12}$ Transplants are usually performed to improve vision and increase the quality of life in patients with damaged or diseased corneas. Corneal transplantation is therefore of significant clinical, biological, and economic relevance. In uncomplicated cases, when the first allografts are performed in avascular beds, the 2 year survival rate is over $90 \% .^{3}$ However, approximately $30 \%$ of the patients undergoing routine penetrating keratoplasty have a rejection episode, and around 10\% of grafts fail because of allograft rejection. ${ }^{1}$ The success rate in "high risk" recipients is much lower and reaches only $35-65 \%$. $^{3}$ Immunological rejection is a leading cause of corneal graft failure. ${ }^{1}$ Patients who have had previous graft failure from rejection have a greater than $50 \%$ chance of subsequent failure; this reaction occurs more rapidly and with a more fulminant course and is directly correlated with the severity of corneal vascularisation. ${ }^{4}$

The extraordinary success of "low risk" penetrating keratoplasty can be attributed to various features of the normal cornea and anterior segment of the eye. The avascular and alymphatic nature of the graft bed, the relative absence of antigen presenting cells (APC), ${ }^{5}$ the production of immunosuppressive factors (such as transforming growth factor (TGF)- $\beta$ and $\alpha$-melanocyte stimulating hormone $(\mathrm{MSH}))^{6}$ by parenchymal and neuronal cells of the iris and ciliary body, the low expression of MHC class II molecules, ${ }^{78}$ the presence of FasL on epithelial and endothelial cells, ${ }^{9}{ }^{10}$ and the induction of immune deviation to corneal antigen $s^{11} 12$ are all features which have been described as contributing to the immune privilege of the anterior segment of the eye.

Corneal epithelial and stromal cells express HLA-A/B/C (class I) antigens. HLA-DR (class II) antigens have been found on Langerhans cells (intraepithelial dendritic cells, DC) (LC) in normal human conjunctiva and corneal limbal epithelium ${ }^{5}$ and in limbal vascular endothelium. ${ }^{13}$ Expression of HLA class II molecules has been found widely distributed on many cell types in pathological corneas. ${ }^{14}$ HLA-A/B/C antigens are thought to act as targets for effector cytotoxic cells during immunological rejection.

There have been several studies of the cellular infiltrate in experimental corneal graft rejection, ${ }^{15-17}$ but few studies have examined closely the infiltrate in rejected human grafts. Pepose et al found that most of the cellular infiltrate comprised $\mathrm{T}$ cells and macrophages 
Table 1 A list of keratoplasty patients used as controls and their characteristics

\begin{tabular}{llllllll}
\hline No & Age & Sex & Reason for keratoplasty & $\begin{array}{l}\text { Postoperative } \\
\text { complication }\end{array}$ & $\begin{array}{l}\text { Rejection } \\
\text { episode }\end{array}$ & $\begin{array}{l}\text { Time after transplantation } \\
\text { and result of the last medical } \\
\text { examination }\end{array}$ & $\begin{array}{l}\text { Postoperative } \\
\text { treatment }\end{array}$ \\
\hline 1 & 43 & F & keratoconus & no rejection & - & 40 months/clear & topical steroids \\
2 & 19 & M & keratoconus & no rejection & - & 60 months/clear & topical steroids \\
3 & 27 & M & keratoconus & no rejection & - & 51 months/clear & topical steroids \\
4 & 33 & M & keratoconus & no rejection & - & 42 months/clear & topical steroids \\
5 & 53 & F & PBK & no rejection & - & 59 months/clear & topical steroids \\
6 & 35 & F & PBK & no rejection & - & 41 months/clear & topical steroids \\
7 & 75 & F & PBK & no rejection & - & 60 months/clear & topical steroids \\
8 & 41 & F & Fuchs endothelial dystrophy & no rejection \\
9 & 60 & F & Fuchs endothelial dystrophy & endoth. rejection & -24 months & 42 months/clear & topical steroids \\
10 & 55 & F & Fuchs endothelial dystrophy & no rejection & - & 42 months/clear & topical steroids \\
& & & & & & & topical steroids \\
\hline
\end{tabular}

$\mathrm{PBK}=$ pseudophakic bullous keratopathy.

and only occasional CD1a (Leu-6) positive cells were found in the corneal epithelium. Larkin et al made similar observations regarding the $\mathrm{T}$ cell and macrophage infiltration, and also investigated the frequency of other cells such as natural killer (NK) cells, but made no reference to dendritic cells. Most of these studies have been performed with the aim of identifying tissue damaging cytotoxic cells. However, the nature of initiating APC involved in corneal graft rejection is still unclear.

Graft rejection generally is considered to occur by both direct and indirect mechanisms. Direct mechanisms are dependent on there being a sufficient population of donor APC and, apart from one report, ${ }^{18}$ the central cornea is generally considered to be devoid of APC. ${ }^{13}$ Rejection, therefore, most likely occurs via the indirect mechanism in which host APC present alloantigen to $\mathrm{T}$ cells. ${ }^{19}$ In corneal grafts the cell which presents the antigen is not known. In only two studies to date were occasional CD1a positive cells detected in the central epithelium of rejected corneal allografts. ${ }^{150}$ CD1a is expressed on LC, a subset of B cells, and cortical thymocytes. Accordingly, it has been suggested that macrophages or even aberrantly MHC class II expressing corneal cells such as the corneal epithelium, endothelium, or keratocytes might act as APC in the rejecting graft.

We have re-examined this question by studying the immunohistochemical staining of the cellular infiltrate in rejecting grafts using dual immunofluorescence to determine whether cells expressing CD1a+, MHC class II+, but negative for CD19, occurred within the reject- ing graft and were therefore in a position to act as profession antigen presenting dendritic cells.

\section{Materials and methods}

PATIENTS

A total of 30 diseased corneas from patients undergoing penetrating keratoplasty were obtained at the 2nd Department of Ophthalmology, Charles University, Prague, after informed consent was given. Investigations were performed according to the guidelines of the Declaration of Helsinki. The clinical details of the corneal recipients (a total of 15 females between the ages of 26-76 years with a median of 53.5 years and 15 males between the ages of 13-74 years with a median of 36.7 years) are given in Tables 1, 2, and 3.

PREPARATION OF TISSUES FOR IMMUNOHISTO-

CHEMISTRY AND IMMUNOFLUORESCENCE

Samples of rejected and explanted corneas were removed, transferred to foil cups containing OCT medium (Miles Corp, Elkhart, IN, USA) and snap frozen in liquid nitrogen cooled isopentane. They were stored at $-80^{\circ} \mathrm{C}$ until used.

IMMUNOHISTOCHEMISTRY

We used the StreptABC method as described previously. ${ }^{21}$ Cryostat sections $(5-6 \mu \mathrm{m})$ of tissues were taken onto chromalum coated slides at $-20^{\circ} \mathrm{C}$ and air dried. The samples were fixed for 10 minutes in acetone, rehydrated twice for 5 minutes in TRIS buffered saline (TBS), and incubated with the primary monoclonal antibody in a humid chamber for 1 hour at room

Table 2 A list of keratoplasty patients with rejected non-inflamed grafts and their characteristics

\begin{tabular}{|c|c|c|c|c|c|c|c|}
\hline No & Age & $\operatorname{Sex}$ & Reason for keratoplasty & $\begin{array}{l}\text { Postoperative } \\
\text { complication }\end{array}$ & $\begin{array}{l}\text { Rejection } \\
\text { episode }\end{array}$ & $\begin{array}{l}\text { Time after transplantation } \\
\text { and result of the last } \\
\text { medical examination }\end{array}$ & Postoperative treatment \\
\hline 11 & 60 & $\mathrm{~F}$ & rejection, graft failure & endothelial rejection & 4 months & 53 months/graft failure & topical steroids \\
\hline 12 & 75 & $\mathrm{~F}$ & rejection, graft failure & no rejection & - & 17 months/clear & topical steroids \\
\hline 13 & 15 & $\mathrm{M}$ & rejection, graft failure & no rejection & - & 36 months/clear & topical steroids \\
\hline 14 & 13 & M & rejection, graft failure & endothelial rejection & 14 months & retransplantation & topical steroids \\
\hline 15 & 67 & $\mathrm{~F}$ & rejection, graft failure & epithelial rejection & 4 months & 31 months/graft failure & topical steroids \\
\hline 16 & 18 & M & rejection, graft failure & stromal rejection & 11 months & retransplantation & topical steroids \\
\hline 17 & 19 & M & rejection, SWP & endothelial rejection & 3 months & retransplantation & topical steroids, systemic acetazolamide \\
\hline 18 & 74 & $\mathrm{M}$ & rejection, SWP & stromal rejection & 9 months & retransplantation & topical steroids \\
\hline 19 & 19 & M & rejection, SWP & graft melting & 1 month & retransplantation & $\begin{array}{l}\text { topical steroids, systemic steroids, systemic } \\
\text { cyclosporine }\end{array}$ \\
\hline 20 & 48 & $\mathrm{~F}$ & rejection, SWP & endoth. rejection & 3 months & 15 months/clear & topical steroids \\
\hline 21 & 19 & $\mathrm{M}$ & rejection, SWP & stromal rejection & 3 months & retransplantation & $\begin{array}{l}\text { topical steroids, parabulbar steroids, } \\
\text { systemic acyclovir, systemic acetazolamide }\end{array}$ \\
\hline 22 & 76 & $\mathrm{~F}$ & rejection, SWP & no rejection & - & 22 months/graft failure & topical steroids \\
\hline 23 & 26 & $\mathrm{M}$ & rejection, SWP & graft melting & 4 months & retransplantation & topical steroids \\
\hline 24 & 70 & $\mathrm{M}$ & rejection, SWP & graft melting & 13 months & retransplantation & topical steroids \\
\hline 25 & 17 & M & rejection, SWP & graft melting & 2 month & retransplantation & topical steroids \\
\hline
\end{tabular}


Table 3 A list of keratoplasty patients with rejected inflamed grafts and their characteristics

\begin{tabular}{|c|c|c|c|c|c|c|c|}
\hline No & Age & Sex & Reason for keratoplasty & $\begin{array}{l}\text { Postoperative } \\
\text { complication }\end{array}$ & $\begin{array}{l}\text { Rejection } \\
\text { episode }\end{array}$ & $\begin{array}{l}\text { Time after transplantation and result } \\
\text { of the last medical examination }\end{array}$ & Postoperative treatment \\
\hline 26 & 71 & M & graft melting & no rejection & - & 16 months/graft failure & topical steroids \\
\hline 27 & 26 & $\mathrm{~F}$ & graft melting & graft melting & 1 month & retransplantation & topical steroids, systemic steroids, systemic cyclosporine \\
\hline 28 & 60 & $\mathrm{M}$ & graft melting & graft failure & 10 months & retransplantation & topical steroids \\
\hline 29 & 26 & $\mathrm{~F}$ & graft melting & graft melting & 1 month & retransplantation & topical steroids, systemic cyclosporine \\
\hline 30 & 66 & $\mathrm{~F}$ & spontaneus perforation & stromal rejection & 1 month & retransplantation & topical steroids, systemic cyclosporine \\
\hline
\end{tabular}

temperature. The monoclonal antibodies (mAb) used are shown in Table 4. The sections were washed twice with TBS and incubated in biotinylated rabbit anti-mouse antibody (diluted 1:100 in TBS containing 5\% normal human serum) for 30 minutes in a humid chamber at room temperature. After washing twice for 5 minutes with TBS, the slides were incubated for 30 minutes with StreptABComplex/AP (Dako, UK) containing streptavidin and biotinylated alkaline phosphatase in TRIS/HCl. After washing, the substrate containing naphthol, levamisol, and fast red (all Sigma, Poole) in veronal acetate buffer was added to the samples. The tissue sections were mounted in Aquamount Improved (BDH, UK).

\section{IMMUNOFLUORESCENCE}

Cryostat sections $(5-6 \mu \mathrm{m})$ of tissues were taken onto chromalum coated slides at $-20^{\circ} \mathrm{C}$ and air dried overnight. The samples were fixed for 10 minutes in acetone and rehydrated twice for 5 minutes in phosphate buffer saline (PBS), then incubated with the primary antibody against CD1a (Becton-Dickinson, UK) in a humid chamber for 30 minutes. The slides were washed three times for 10 minutes with PBS and incubated with a secondary biotinylated rabbit anti-mouse antibody (diluted 1:100 in PBS containing 5\% normal human serum), for 30 minutes. After washing three times for 10 minutes with PBS, the slides were incubated for 30 minutes with Streptavidin-Texas Red (Amersham) diluted 1:50 in PBS. After further three washes for 10 minutes in PBS, the slides were incubated with the primary antibody against CD19 (Dako, $\mathrm{UK}$ ) or mAb anti-MHC class II molecules

Table 4 A list of primary $m A$ bs used for immunohistochemistry

\begin{tabular}{llll}
\hline$m A b$ & Source & Isotype & Dilution \\
\hline CD1a & Becton-Dickinson & $\mathrm{IgG}_{1}$ & $1 / 5$ \\
CD3 & SAPU & $\mathrm{IgG}_{1}$ & $1 / 10$ \\
CD4 & SAPU & $\mathrm{IgG}_{1}$ & $1 / 10$ \\
CD8 & SAPU & $\mathrm{IgG}_{1}$ & $1 / 10$ \\
CD14 & SAPU & $\mathrm{IgG}_{1}$ & $1 / 10$ \\
CD19 & DAKO & $\mathrm{IgG}_{1}$ & $1 / 20$ \\
CD25 & DAKO & $\mathrm{IgG}_{1}$ & $1 / 20$ \\
CD68 & Serotec & $\mathrm{IgG}_{1}$ & $1 / 10$ \\
HLA-DR(B-D) & SAPU & $\mathrm{IgG}_{2 a}$ & $1 / 10$ \\
HLA-DP(B-D) & Becton-Dickinson & $\mathrm{IgG}_{1}$ & $1 / 50$ \\
& & & \\
\hline
\end{tabular}

(Sapu, UK or Becton Dickinson, USA) as before. The slides were then washed three times for 10 minutes with PBS and incubated for 30 minutes with the second secondary antibody, FITC labelled rat anti-mouse immunoglobulin (diluted 1:50 in PBS containing 5\% normal human serum). After washing three times for 10 minutes with PBS, the tissue sections were mounted in Vectashield (Vector Laboratories, CA, USA). We used three kinds of negative controls: (1) tissue sections stained without the first primary $\mathrm{mAb}$; (2) sections stained without the second primary $\mathrm{mAb}$, and (3) sections stained without both primary $\mathrm{mAb}$. Instead of primary antibodies we used PBS for the negative control staining.

LIGHT MICROSCOPY

Tissue sections were examined by light microscopy (Olympus-CH-2, Japan) and immunofluorescence microscopy (Olympus, Japan). Samples were examined using a $\times 200$ original magnification.

\section{HISTOLOGICAL SCORING}

The number of cells per $20 \times$ objective field was graded as follows: $0=$ no positive cells observed; $1=1-10$ positive cells/field; $2=$ 11-20 positive cells/field; $3=21-30$ positive cells/field; and $4=>30$ positive cells/field. The samples were evaluated by two masked observers. Statistical analysis was performed used a Student's unpaired $t$ test.

\section{Results}

The results of the immunohistological analysis of test corneal sections are summarised in Table 5. All 10 control corneal buttons (explanted for keratoconus, Fuchs' endothelial dystrophy, and pseudophakic bullous keratopathy) were negative for the set of antibody markers studied (CD3, CD4, CD8, CD14, CD25, CD68) (Fig 1A). No inflammatory cells were seen and no HLA class II molecules were detected on the surface of epithelial, stromal or endothelial cells. There was also no evidence of LC or DC (CD1a/MHC class II double positive cells) in the corneal tissue.

The rejected, failed grafts from noninflamed "quiet" eyes showed moderate positivity for CD14, CD68 (average grade 2.14 (SD 1.7) and $2.0(1.24)$ ), and CD8 (average

Figure 1(A) Corneal specimen obtained from a patient with keratoconus stained mAb anti-CD68 (original magnification $\times 100$ ). No staining was observed. (B) Strongly positive MHC class II cells (HLA-DR) in the deep layer of the corneal epithelium and in the stroma from a rejected cornea clinically showing no inflammation at the time of surgery (original magnification $\times 400)$. (C) MHC class II (HLA-DP) positive cells in the superficial layers of the epithelium from same specimen as (B) (original magnification $\times 200$ ). (D) Corneal explant obtained from patient after keratoplasty " $a$ chaud" (in severe inflammation at time of surgery). Specimen shows strong staining for macrophages (mAb anti-CD68) especially around the suture (arrow) (original magnification $\times 400)$. (E) Patchy MHC class II (HLA-DR) positive staining of endothelial cells from same specimen as (D) (original magnification $\times 600)$. (F) Intensive staining for MHC class II (HLA-DR) on dendritic-like cells in stroma of a corneal specimen from patient with epithelial wound healing problems and no inflammation at the time of corneal transplantation (original magnification $\times 600$ ). Dual immunofluorescent staining of corneal stromal cells with MHC class II (HLA-DR) and CD1a. (G) Widespread MHC class II staining of many cells in corneal stroma. Arrows show dendritic-like cells in corneal stroma. (H) CD1 a staining of individual cells from same region as (G). (I) Dual overlay showing co-expression of MHC Class II and CD1a on stromal dendritic cells, same field as $(G)$ and $(H)$ (original magnification $\times 600)$. 

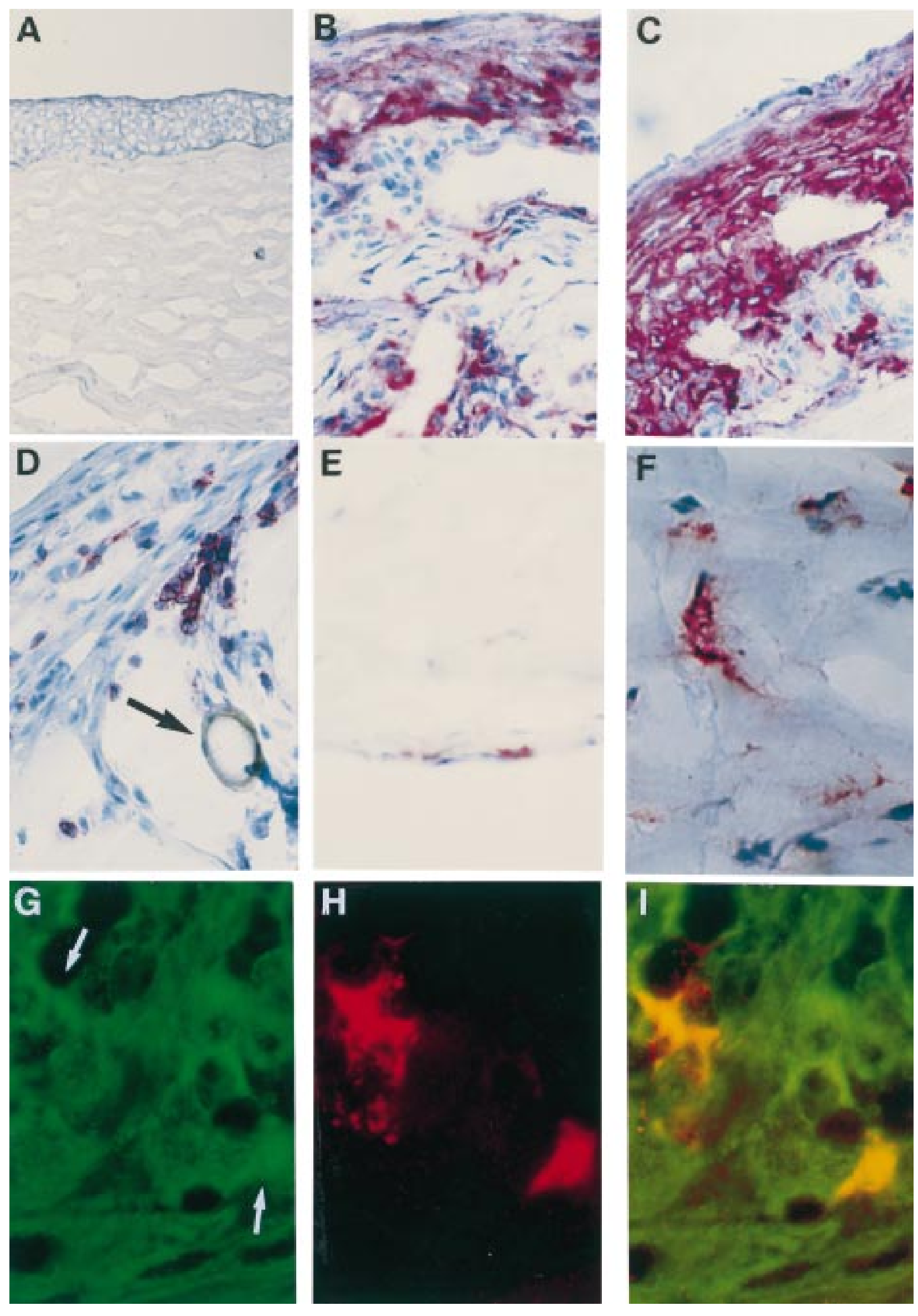

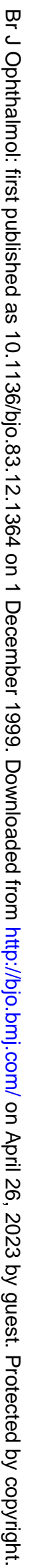


Table 5 Analysis of antibody staining in grafted corneas

\begin{tabular}{|c|c|c|c|c|c|c|c|c|c|}
\hline \multirow[b]{2}{*}{ Patient group } & \multicolumn{9}{|c|}{ Grade of antibody staining } \\
\hline & $C D 3$ & $C D 4$ & CD8 & $C D 14$ & $C D 68$ & $C D 25$ & $H L A-D R$ & $H L A-D P$ & CD1a/MHC class II \\
\hline Group $1(n=10)$ & $0^{\star}$ & 0 & 0 & 0 & 0 & 0 & 0 & 0 & 0 \\
\hline Group $2(n=15)$ & $0.67(1.17)$ & $0.37(0.61)$ & $0.87(0.83)$ & $2.14(1.70)$ & $2(1.24)$ & $0.47(0.51)$ & $2.8(1.33)$ & $2.27(1.33)$ & $1.34(1.16)$ \\
\hline Group $3(n=5)$ & $2(0.63)$ & $0.80(0.74)$ & $1.8(0.74)$ & $3(0.89)$ & $3.8(0.89)$ & $0.8(0.4)$ & $3.4(0.8)$ & $3.2(0.74)$ & $1(1.09)$ \\
\hline $\mathrm{p}$ Value & $0.005 t$ & 0.128 & $0.034 \dagger$ & 0.101 & $0.05 t$ & 0.101 & 0.198 & $0.046 \dagger$ & 0.309 \\
\hline
\end{tabular}

${ }^{\star}$ Grades $0-4$ based on actual cell counts in tissue sections (see Methods). Scores represent mean grade (SD) with $\mathrm{n}=$ number of samples as indicated.

†Significance of differences between group 2 (clinically no inflammation) and group 3 (clinically inflamed) patients. Statistics were not applied to data combining groups 1 and 2 and groups 1 and 3 since no inflammatory cells were observed in the dystrophic corneas and they are clearly different (score zero).

grade $0.87(0.83)$ ) and strong positivity for HLA class II molecules HLA-DP and HLA-DR (average grade 2.27 (1.33) and 2.8 (1.33)) (Fig $1 \mathrm{~B}$ and $\mathrm{C}$ ). The presence of HLA-DR positivity was found particularly on cells in the basal layers of the corneal epithelium and in the stroma, and on corneal endothelial cells (Fig 1E). Staining for CD3 and CD4 was negative or low in the majority of grafts. CD1a/MHC class II double positive cells were localised in the deep epithelial layer at the level of Bowman's membrane and also in the corneal stroma.

The grafts collected from eyes with active inflammation "melts" (keratoplasty "a chaud") showed moderate positivity for CD3, CD4, and CD8 (average grade 2.0 (0.63), 0.8 (0.74), and $1.8(0.74)$ ), a level which was significantly greater than that in the rejected "quiet" explants. The majority of corneal grafts were strongly positive for the macrophage markers CD14 and CD68 (average grade $3.0(0.89)$ and $3.8(0.89)$ ) (Fig 1D) and for HLA-DP and HLA-DR (average grade $3.2(0.74)$ and 3.4 (0.8)). CD1a/MHC class II expressing double positive cells were present in significant number in the deep epithelial layer and throughout the corneal stroma (Fig 1G, H, I and Table 5). Staining for CD19 was also performed and only a few cells expressing this marker were detected. Dual staining for CD1a and CD19 was also performed and no co-expression detected (data not shown).

In the control group $(n=10)$ we observed immunological rejection in $10 \%$ of the patients. In the group with previous graft rejection, but no inflammation in the eye at the time of regrafting $(n=6), 66.7 \%$ of subjects had a rejection episode followed by graft failure, while $33.3 \%$ achieved long term acceptance of the graft. In the same group with previous rejection, but who were complicated by having surface wound healing problems without inflammation at the time of rekeratoplasty $(n=9)$, rejection occurred in $44.4 \%$ of patients, graft melting in $44.4 \%$, and only $11.2 \%$ achieved long term acceptance of the graft. In this group $88.8 \%$ of patients suffered graft failure and $77 \%$ of these failed grafts required regrafting. In the group with active inflammation at the time of grafting and who also had surface wound healing problems with graft melting $(n=5), 60 \%$ of subjects suffered a further melting of the graft and further $20 \%$ rejected their graft. All subjects have achieved graft failure and only one of these cases did not required regrafting.

\section{Discussion}

Immunological rejection is the most important cause of graft failure in corneal transplantation. ${ }^{1}$ Since there are only limited data on cells which might mediate the immune response particularly antigen presentation in the eye, we measured the expression of HLA-DR and HLA-DP molecules and looked for the presence of DC and macrophages in the corneal buttons from rejected and melted corneal grafts and from control corneas. In this report, for the first time dual immunofluorescent staining has been used for detection of DC using positivity with MHC class II and CD1a and negativity with CD19 antigens as criteria. In a previous paper, low numbers of CD1a+ cells were observed in the corneal epithelium, but not in the corneal stroma. ${ }^{15}{ }^{20} \mathrm{We}$ observed a population of cells which were MHC class II+, CD1a+, CD19-, had a dendritic morphology in corneal epithelial layer but also in the corneal stroma, and which we believe to be definitive dendritic APC. The source of these cells may be from migrating limbal LC, which have become activated, or from conjunctival stromal DC, which have been recruited from bone marrow.

In the group of 15 corneal buttons examined after rejection (from eyes with no inflammation), a significantly less intense infiltration of CD3, CD4, and CD8 positive cells was found in comparison with explants with severe inflammation. However, prominent expression of HLA-DR and HLA-DP antigens on tissue resident cells was seen in a majority of rejected grafts. It is possible that the expression of class II HLA molecules on the non-professional APC might be induced by cytokines produced by inflammatory cells, as has been proposed, ${ }^{15}$ and we have observed extensive MHC class II expression on epithelial, stromal, and even on endothelial cells. However, since antigen presentation requires not only MHC class II antigen upregulation but also expression of co-stimulatory molecules, it is unlikely that MHC class II antigen alone on tissue cells is responsible for alloantigen presentation to cytotoxic T cells.

We suggested therefore that professional DC are responsible for initiating graft rejection. The number of CD1a/MHC class II double positive cells was not significantly higher in a group with severe inflammation at the time of surgery than in the group with no inflammation. The number of macrophages, which were also regularly observed in rejected corneas, was variable. We have found significantly increased numbers of CD68+ cells in the severely 
inflamed corneas. These cells may also act locally as APC within the corneal graft and thus perpetuate the rejection reaction, but macrophages are 100 times less potent as APC than DC. ${ }^{22}$ In addition, it is likely that the influx of macrophages may be secondary to the release of a variety of cytokines and chemokines produced by the graft infiltrating lymphocytes. One of these cytokines, migration inhibitory factor (MIF), is produced by many cells including corneal cells. ${ }^{23}$

The most important clinical question is the long term acceptance of the corneal graft. From previous studies reduced corneal graft survival time was observed in recipients with grafts containing high numbers of APC. ${ }^{17}$ In this study we have found immunological rejection followed by graft failure in $66.7 \%$ and $88.8 \%$ respectively of subjects in the group with no inflammation at the time of surgery. All subjects with severe inflammation in the time of surgery developed graft failure and in $80 \%$ underwent repeated corneal transplantation.

More extensive studies on the composition of graft infiltrating lymphocytes have been done in rat cornea, which closely resembles human cornea in terms of MHC molecule expression. ${ }^{24}$ It was shown that transplantation of syngeneic grafts evokes a focal inflammatory reaction in the vicinity of the sutures and in the wound. ${ }^{25}$ Allogeneic grafts induce diffuse inflammation with $\mathrm{CD} 8+$ and $\mathrm{CD} 4+1 \mathrm{ym}-$ phocytes and macrophages. The ratio of $\mathrm{CD} 8+$ to CD4+ lymphocytes changes with time after grafting, being higher immediately after grafting. ${ }^{26}$

Taken together, the results of this study support the view that early non-specific inflammation such as occurs in association with surface wound healing problems, previous corneal graft "melting", and even sutures in the cornea may lead to amplification of the inflammatory response and may trigger an immune response in the eye mediated by CD1a+ and MHC class II+ professional APC. This then leads to chemoattraction of antigen specific and nonantigen specific $T$ cell populations with further tissue damaging macrophage infiltration and finally graft rejection.

This work was supported by grant No IZ/4185-3 from the ministry of health of the Czech Republic and grant No 310/97/1261 from the grant agency of the Czech Republic.

We wish to thank Vera Veselá, MD, for her expert technical assistance.

Presented as a poster at the Association for Research in Ophthalmology and Visual Sciences Annual Meeting, 1998.
1 Council of Scientific Affairs. Report of the Organ Transplant Panel-Corneal Transplantation. $f A M A$ plant Panel-

2 Brady SE, Rapuano JC, Arentsen JJ, et al. Clinican indication and procedures associated with penetrating keratoplasty. Am f Ophthalmol 1989;108:118-22.

3 CCTS. The Collaborative Corneal Transplantation Studies Research Group. Arch Ophthalmol 1992;54:1392-403.

4 Khodadoust AA. Corneal graft failure. Ciba Foundation Symposium 1973. Amsterdam: Elsevier, Excerpta Medica, 1973:161-75.

5 Fujikawa LS, Calvin RB, Bhan AK, et al. Expression of HLA-A/B/C and -DR locus antigens on epithelial, stromal and endothelial cells of the human cornea. Cornea 1982;1: 213-22.

6 Ferguson TA, Fletcher S, Herndon J, et al. Neuropeptides modulated immune deviation induced via the anterior chamber of the eye. I Immunol 1995;55:1746-56

7 Whitsett CF, Stulting RD. The distribution of HLA antigens on human corneal tissue. Invest Ophthalmol Vis Sci $1984 ; 25: 519-24$.

8 Klareskog L, Forsum U, Tjerlund UM, et al. Expression of la-like molecules on cells in the corneal epithelium. Invest Ophthalmol Vis Sci 1979;18:310-3.

9 Stuart PM, Griffith TS, Usui N, et al. CD95 ligand (Fas-L)induced apoptosis is necessary for corneal allograft induced apoptosis is necessary for

10 Ju ST, Panka DJ, Cui H, et al. Fas (CD95)/Fas-L interaction required for programmed cell death after T-cell activation. Nature 1995;373:444-8.

11 Joo CK, Pepose JS, Stuart PM. T-cell mediated responses in murine model of orthotopic corneal transplantation. Invest Ophthalmol Vis Sci 1995;36:1530-40.

12 Sonoda Y, Streilein JW. Impaired cell-mediated immunity in mice bearing healthy orthotopic corneal allografts. F Immunol 1993;150:1727-34.

13 Pels E, van der Gaag R. HLA-A,B,C, and HLA-DR antigens and dendritic cells in fresh and organ culture preserved corneas. Cornea 1985;3:231-9.

14 Delbosc B, Fellmann D, Piquot X, et al. Antigénicité HLA des cornées humaines normales et pathologiques. $\mathcal{F ~ F r}$ Ophtalmol 1990;11:535-41.

15 Pepose JS, Nestor MS, Gardner KM, et al. Composition of cellular infiltrates in rejected human corneal allografts. Graefes Arch Exp Ophthalmol 1985;222:128-33.

16 Larkin DFP, Alexander RA, Cree IA. Infiltration inflammatory cell phenotypes and apoptosis in rejected human corneal allografts. Eye 1997;11:68-74.

17 Williams KA, White MA, Ash JK, et al. Leukocytes in the graft bed are associated with corneal graft failure: analysis by immunohistology and actuarial graft survival. Ophthalmology 1989;96:38-44.

18 Williams KA, Ash JK, Coster DJ. Histocompatibility antigen and passenger cell content of normal and diseased human cornea. Transplantation 1985;39:265-9.

19 Nicholls SM. Non-HLA antigens and HLA-DR matching in corneal transplantation. Br f Ophthalmol 1996;80:780-2.

20 Catry L, Van den Oord J, Foets B, et al. Morphologic and immunophenotypic heterogeneity of corneal dendritic immunophenotypic heterogeneity of corneal de

21 Forrester JV, McMenamin PG, Holthouse I, et al. Localization and characterization of major histocompatibility complex class II-positive cells in the posterion segment of the eye: implications for induction of autoimmune uveoretinitis. Invest Ophthalmol Vis Sci 1994;35:64-73.

22 Steinman RM. The dendritic cell system and its role in immunogenicity. Annu Rev Immunol 1991;9:271-96.

23 Matsuda A, Tagawa $\mathrm{Y}$, Matsuda $\mathrm{H}$, et al. Identification and immunohistochemical localization of macrophage migration inhibitory factor in human cornea. FEBS Lett 1996;385:225-8.

24 Treserer PA, Sanfillipo F. The expression of major histocompatibility complex and leucocyte antigens by cells in the rat cornea. Transplantation 1986;41:248-52.

25 Holland EJ, Chan C-C, Wetzig RP, et al. Clinical and immunohistologic studies of corneal rejection in the rat penetrating keratoplasty model. Cornea 1991;10:374-80.

26 Larkin DFP, Calder VL, Lightman SL. Identification and characterization of cell infiltrating the graft and aqueous humour on rat corneal allograft rejection. Clin Exp Immunol 1997;107:381-91. 